\title{
THE EFFECT OF SYNTHETIC FUNGICIDE ON DISEASE SEVERITY AND PLANT GROWTH OF CHILI PEPPER (Capsicum annuum L.) INFECTED WITH Phytophthora capsici
}

\author{
RIZKITA RACHMI ESYANTI ${ }^{1 *}$, NADYA FARAH ${ }^{1,3}$, MUHAMMAD FAKHRI FAIZ $^{1}$, \\ MUTHIA GASSANI VERDIANTI ${ }^{1}$, SUNARDI ${ }^{2}$ and RAMADHANI SAFITRI ${ }^{2}$ \\ ${ }^{I}$ School of Life Sciences and Technology, Institut Teknologi Bandung, Indonesia \\ ${ }^{2}$ East West Seed, Indonesia \\ ${ }^{3}$ Bali International Research Center for Banana, Indonesia \\ *E-mail: rizkita@sith.itb.ac.id
}

Accepted 15 May 2020, Published online 6 July 2020

\begin{abstract}
Phytophthora blight caused by Phytophthora capsici is one of the damaging diseases that cause major loss in chili pepper (Capsicum annuum L.) production worldwide. Some synthetic fungicides containing Metalaxyl-M were reported to be able to control the pathogen's growth. In order to evaluate the effect of synthetic fungicide on disease severity index (DSI) and plant growth of chili pepper plants after inoculation with $P$. capsici $\left(10^{4}\right.$ zoospores $\left./ \mathrm{ml}\right)$, four cultivars were used namely Laba, Pilar, Arimbi and Imola. Each cultivar was treated with a synthetic fungicide and $P$. capsici (FP), with $P$. capsici-only (P) and uninoculated plants $(\mathrm{C})$ were used as controls. The result showed that the application of synthetic fungicide was able to control the pathogen's growth, indicated by the decreased DSI. The application of synthetic fungicide was also able to preserve the growth of chili pepper plants, indicated by the plant height and number of leaves, even after the infection with $P$. capsici. In conclusion, the application of synthetic fungicide was effective in controlling the growth of $P$. capsici while preserving the growth of chili pepper plants in cultivar Pilar, Imola, Laba, and Arimbi.
\end{abstract}

Key words: Phytophthora blight, chilli pepper, synthetic fungicide

\section{INTRODUCTION}

Chili pepper is one of the important horticultural commodities in Indonesia with an average consumption that reaches $1.34 \mathrm{~kg}$ per capita per year (BPS, 2015). However, the productivity of chili pepper in Indonesia was considerably low (6.84 tonnes/ha/year) based on the data from Badan Pusat Statistik (BPS) in 2012 (Rusono et al., 2013). The low productivity of chili pepper was mostly due to diseases, with Phytophthora blight caused by the oomycete of Phytophthora capsici Leonian as the biggest threats (Ristaino \& Johnston, 1999). The pathogen is able to attack all parts of the chilli pepper plant (roots, stems, leaves, and fruits) in all developmental stages (Biles et al., 1993; Lefebvre \& Palloix, 1996; Shannon, 1989). Initially, the infected leaves will show a minor round or irregular lesion which then enlarges, dries and turns white to light brown (Alcantara \& Bosland, 1994). In

\footnotetext{
* To whom correspondence should be addressed.
}

addition, a blackish brown lesion is formed on the stem. The root and stem will be blackened and the infected plants are often collapsed (Gevens et al., 2015). The infected fruit will be withered and rotten. Furthermore, the fruit will turn white, and the mycelium of $P$. capsici can be found inside the infected fruit (Hwang \& Kim, 1995).

One way to control the disease is by using synthetic fungicides that contain metalaxyl-M as an active ingredient (Ristaino \& Johnston, 1999). Hence, in order to evaluate the effect of synthetic fungicide (metalaxyl-M) on disease severity index (DSI) and plant growth of chili pepper plants after inoculation with $P$. capsici, four chili cultivars were used namely Laba, Pilar, Arimbi and Imola.

\section{MATERIALS AND METHODS}

\section{Experimental condition}

The experiment was conducted in the plant pathology screen house at Purwakarta, Jawa Barat, 
Indonesia (lat. 06³0'47.7'N, long. 107²9'39.6”E, $69 \mathrm{~m}$ a.s.1.) in a uniform cultural condition. The four chili cultivars tested were Pilar, Imola, Laba, and Arimbi. Chili cultivars that are known to be susceptible and resistance were used as controls.

\section{Fungicide application}

Fungicide with active ingredients of $4 \%$ mefenoxam (Metalaxyl-M) and 64\% mankozeb was used. The fungicide with the concentration of 2.5 $\mathrm{g} / \mathrm{L}$ was applied on chilli cultivars using foliar spray method every week started from 2 weeks prior to $P$. capsici inoculation.

\section{Inoculation of $\boldsymbol{P}$. capsici}

$P$. capsici inoculum was prepared as described by Akgül and Mirik (2008) with some modifications. $P$. capsici isolates were grown on Potato Dextrose Agar (PDA) media and incubated in $25^{\circ} \mathrm{C}$ for 7 days. After 7 days of incubation, the plates were incubated under fluorescent light with the same temperature for 3 days to stimulate sporangial formation. The cells were then counted using haemocytometer and diluted with distilled water until the concentration of the zoospore suspension was $10^{4}$ zoospores $/ \mathrm{ml}$. After 2 weeks of fungicide application, $5 \mathrm{ml}$ of the zoospore suspension was inoculated directly to the plant growth media using a syringe. The treated plants were then designated as an FP (Fungicide and $P$. capsici) whereas uninoculated plants (C) and $P$. capsici-only inoculated plants $(\mathrm{P})$ were used as controls. Each treatment was prepared as five replicates.

\section{Disease assessment}

The effect of fungicide application on inhibiting the pathogen's growth was observed visually using a disease index as described by Akgül and Mirik (2008) with 0-5 scale with some modification where 0 : no visible disease symptom from pathogen; 1: brown lesions appear on the base of the stem; 2: $10-40 \%$ of entire plant diseased; 3 : $40-60 \%$ of entire plant diseased; $4: 60-90 \%$ of entire plant diseased; and 5: dead plant $(100 \%$ of entire plant diseased). Disease index measurement was carried out every three days. The index was used to determine the disease severity index percentage (DSI \%) using Townsend - Heuberger formula (Lo Scalzo et al., 2012):

$$
\operatorname{DSI}(\%)=\frac{\sum_{1}^{i}\left(n_{i} \times v_{i}\right)}{N \times V}
$$

where $n_{i}$ is the number of plant in one group of disease index, $\mathrm{v}_{\mathrm{i}}$ is the damage score, $\mathrm{N}$ is the total number of plants, and $\mathrm{V}$ is the highest disease index found in the experiment (highest index is 5 in this experiment).

\section{Chili plant growth parameters}

Plant growth parameters were also measured to evaluate the effect of pathogen on the growth of chili pepper plants with and without the fungicide application. Plant height and number of leaves were noted on each treatment and cultivar. Measurement of the plant growth parameters was conducted once a week.

\section{RESULTS AND DISCUSSION}

\section{Disease severity}

Disease severity on chilli pepper plants towards $P$. capsici was scored from 0 to 5 and observed on chili leaves (Figure 1). The disease severity index (DSI) was then observed on four chilli cultivars: Laba, Arimbi, Pilar and Imola after infection with the $P$. capsici (Figure 2). As shown in Figure 2, Arimbi had the highest percentage of DSI compared
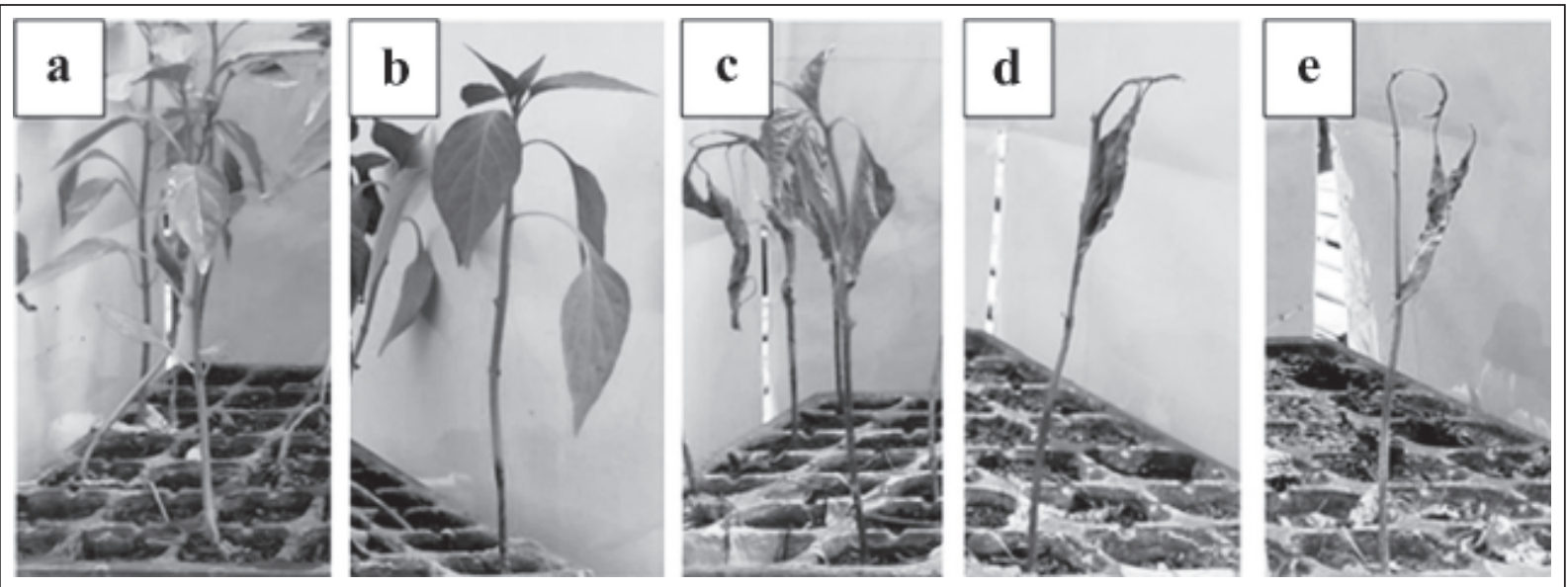

Fig. 1. Disease index visualization: a) score 1, b) score 2, c) score 3, d) score 4, e) score 5. 
to all cultivars including the susceptible control plants on the 3rd day after inoculation, but then decreased on day 12 after inoculation. The percentage of disease severity in Arimbi, Pilar and Imola were also higher compared to Laba. Thus, Pilar, Imola, and Arimbi cultivars are considered to be susceptible cultivars, whereas Laba was considered in the moderate level (between the resistance and susceptible control cultivars).

The percentage of disease severity in cultivar Laba was lower compared to the other three cultivars (Pilar, Imola, and Arimbi) on the $6^{\text {th }}$ day when treated with $P$. capsici, as shown in Figure 2.
However, the percentage increased over time and so chili plants cultivar Pilar, Imola, and Arimbi did not survive till the last day of observation $\left(28^{\text {th }}\right.$ days after inoculation with $P$. capsici). On the contrary, the DSI was not high when the plants were treated with the synthetic fungicide (Figure 3 ). The fungicide was proven to be able to suppress the growth of $P$. capsici, indicated by the low level of DSI. Further observation showed that when all cultivars treated with synthetic fungicide were compared, the percentage of disease severity on chili pepper cultivars was as follow: Laba $<$ Pilar $<$ Arimbi $<$ Imola (Figure 3).

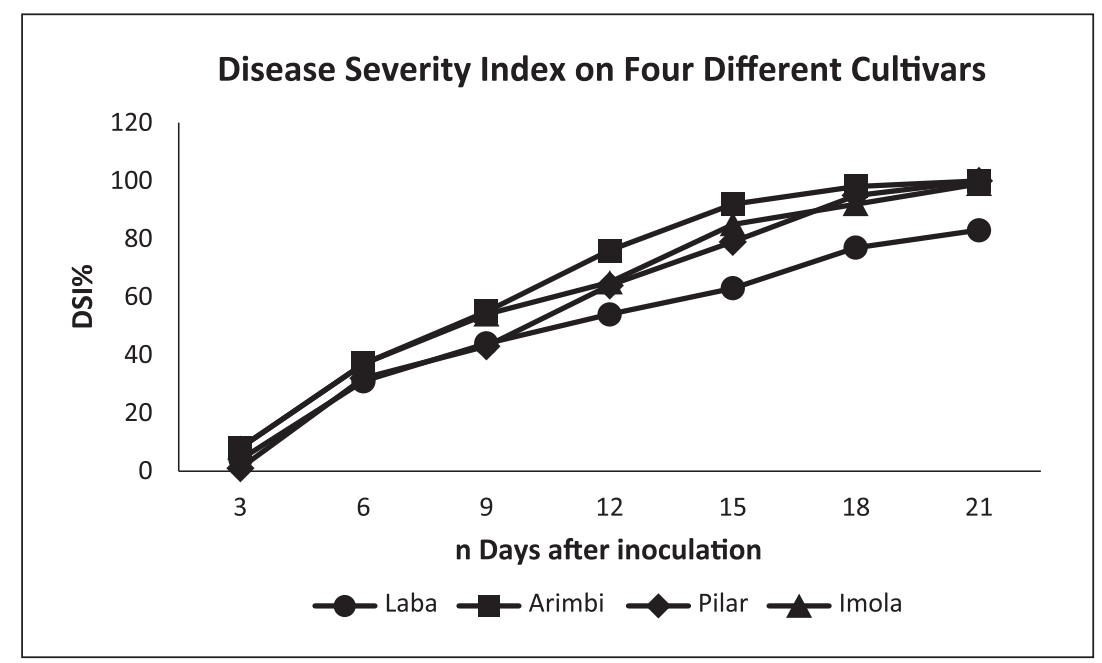

Fig. 2. Disease Severity Index percentage (DSI\%) of four different chili cultivars infected by $P$. capsici.

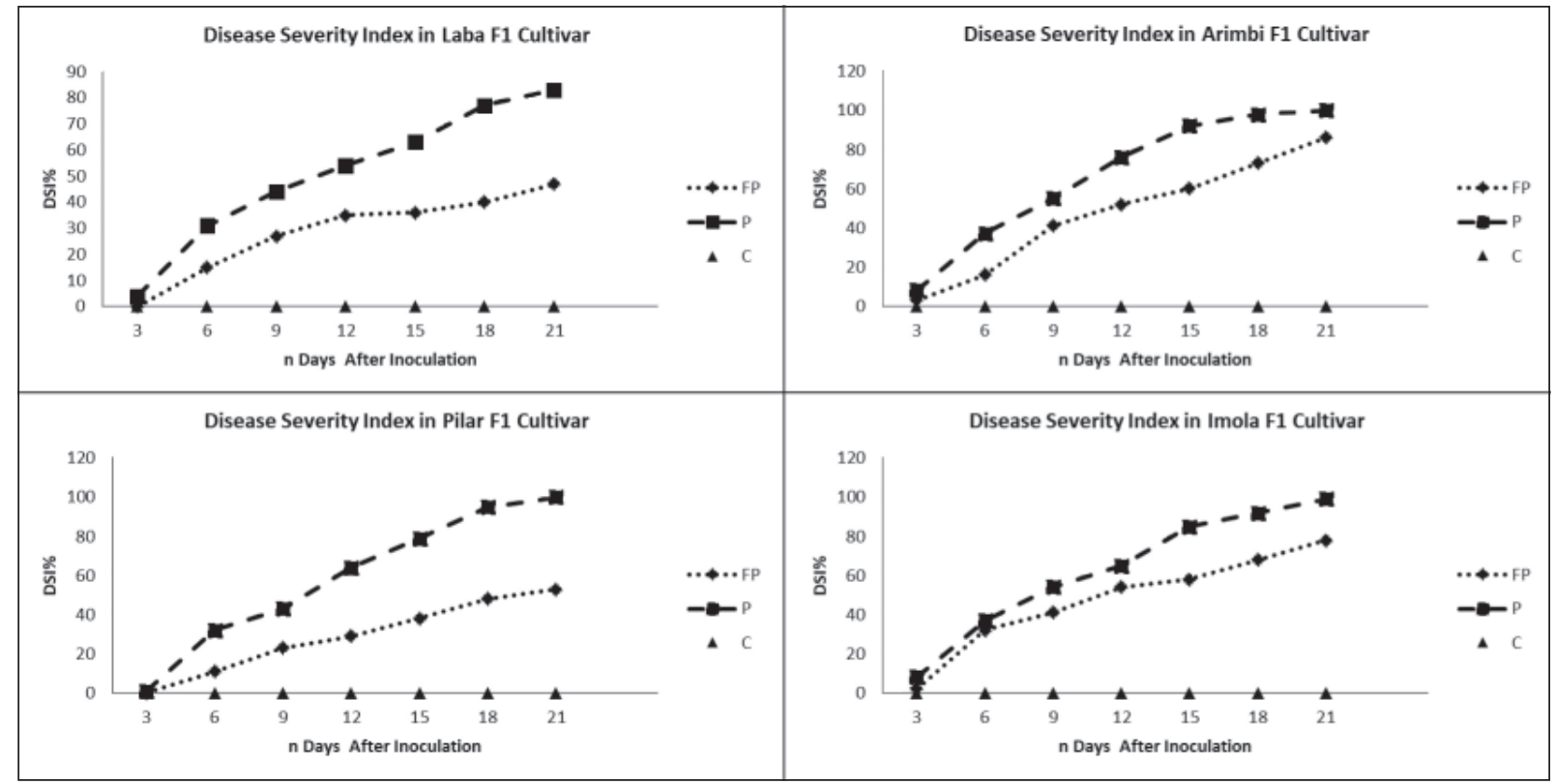

Fig. 3. Percentage of disease severity on four cultivars using different treatment (FP: Fungicide + inoculated with $P$. capsici; P: inoculated with P. capsici; C: control). 
Based on the results in Figure 3, chili cv. Arimbi was initially the most susceptible one, but the application of synthetic fungicides was likely to be able to control the infection of $P$. capsici until the $6^{\text {th }}$ day after inoculation. The active ingredient metalaxyl-M worked systemically (Cohen \& Coffey, 1986). When synthetic fungicide is applied as foliar spray, the compound is absorbed and translocated through the plant vascular tissues with the upward movement along with the transpiration stream (Edgington \& Peterson, 1977). The mode of action of this compound is by inhibiting the RNA synthesis of $P$. capsici. It is known that metalaxyl-M is also able to inhibit the formation of sporangium, chlamidospore, and oospore (Cohen \& Coffey, 1986). Based on Figure 3, it showed that the percentage of the disease severity continuously increased in all cultivars, which could be an indication that foliar applications of synthetic fungicide did not give a big impact in reducing the disease severity for a disease that developed in the root zone. The active ingredients metalaxyl-M contained in these synthetic fungicides might not be transported into the root zone (Guest et al., 1995). The results also showed that the resistance of chili pepper plant against fungal infection of $P$. capsici was influenced by two factors: internal (genetic) and external (synthetic fungicide application) factors. Naturally, chili pepper plants have CaRGA-2 resistance gene expressed when the plants are infected by $P$. capsici (Zhang et al., 2013) and so synthetic fungicide could further inhibit the $P$. capsici when natural resistance was not effective to inhibit pathogen infection.

\section{Plant height and number of leaves as growth parameters}

Plant growth parameters such as the plant height and number of leaves were observed in four chili cultivars on all treatments (Figure 4 and Figure 5). The growth of control plants, not inoculated with pathogen $P$. capsici (C), was normal and did not show any growth inhibition. Synthetic fungicide application (FP) resulted in a better growth response on chili cv. Laba and Pilar compared to the plant inoculated with $P$. capsici $(\mathrm{P})$. Plant growth inhibition was one of the symptoms that plants were infected by $P$. capsici on the root and thus causing root rot (Candole et al., 2010), which might inhibit nutrient absorption. Another symptom of Phytophthora wilt was leaf drop and wilting (Candole et al., 2010). Figure 5 showed the average number of leaves in each treatments and cultivars. Similar to the plant height, synthetic fungicide application (FP) also resulted in a higher number of leaves than the pathogen-inoculated plants $(\mathrm{P})$.

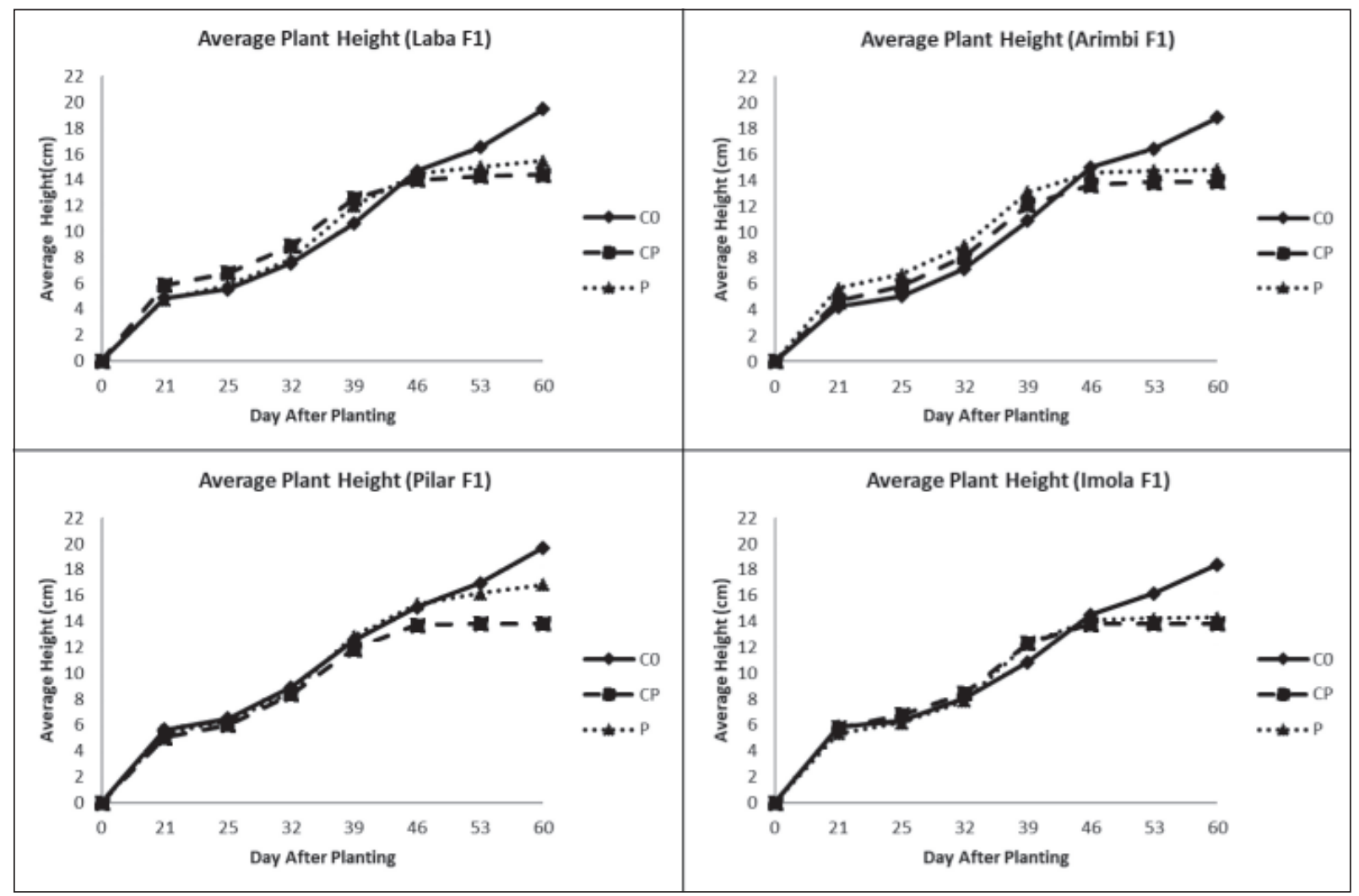

Fig. 4. Average of chili pepper plant height on different treatment (CP: Fungicide + inoculated with P. capsici; P: inoculated with $P$. capsici; CO: control). 


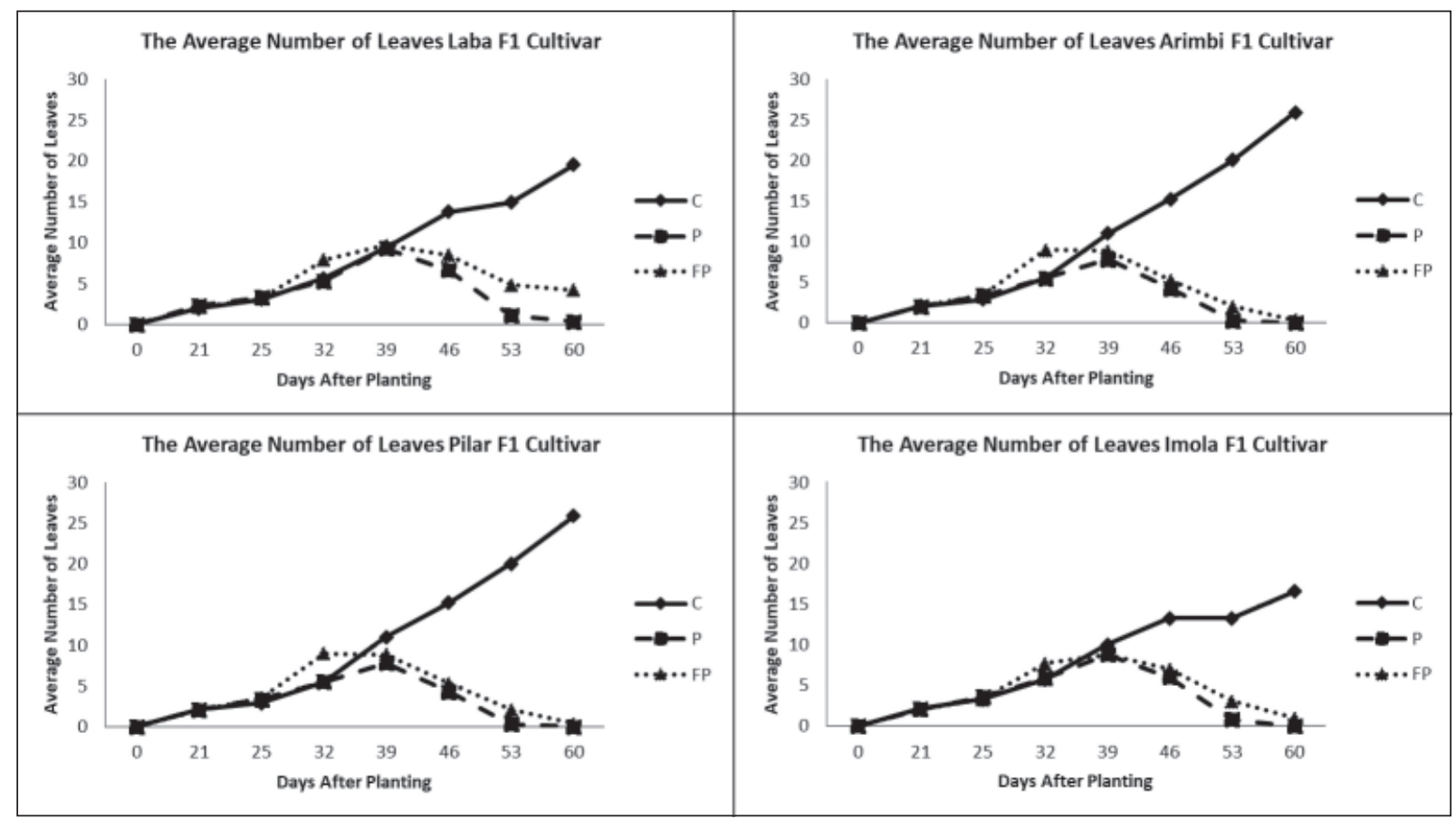

Fig. 5. Average of chili pepper plant leave number on different treatment (FP: Fungicide + inoculated with $P$. capsici; P: inoculated with P. capsici; C: control).

Overall, the application of synthetic fungicide was able to control the $P$. capsici infection on four cultivars of chili pepper plants, indicated by the decreased number of DSI. The synthetic fungicide application could also maintain the chili pepper plant growth, indicated by the plant height and number of leaves, even after the infection by $P$. capsici.

\section{ACKNOWLEDGEMENTS}

This research was funded by IPTEK DIKTI for the year 2016. Special thanks to PT. East West Seed Indonesia for providing in-kind assistance for this research.

\section{REFERENCES}

Akgül, D.S. \& Mirik, M. 2008. Biocontrol of Phytophthora capsici on pepper plants by Bacillus megaterium strains. Journal of Plant Pathology, 90(1): 29-34.

Alcantara, T.P. \& Bosland, P.W. 1994. An inexpensive disease screening technique for foliar blight of chile pepper seedlings. Hort Science, 29(10): 1182-1183.
Biles, C.L., Wall, M.M., Waugh, M. \& Palmer, H. 1993. Relationship of Phytophthora fruit rot to fruit maturation and cuticle thickness of New Mexican-type peppers. Physiology and Biochemistry, 83(6): 607-611.

Candole, B.L., Conner, P.J. \& Ji, P. 2010. Screening Capsicum annuum accessions for resistance to six isolates of Phytophthora capsici. Hort Science, 45(2): 254-259.

Cohen, Y. \& Coffey, M.D. 1986. Systemic fungicides and the control of oomycetes. Annual Review of Phytopathology, 24: 311-338.

Edgington, L.V. \& Peterson, C.A. 1977. Antifungal Compounds. Marcel Dekker, New York, USA, Marcel Dekker.

Gevens, A.J., Roberts, P.D., McGovern, R.J. \& Kucharek, T.A. 2015. Vegetable Diseases Caused by Phytophthora capsici in Florida. Plant Pathology Department, University of Florida.

Guest, D.I., Pegg, K.G. \& Whiley, A.W. 1995. Control of Phytophthora diseases of tree crops using trunk-injected phosphonates Horticultural Reviews, 17: 299-330.

Hwang, B.K. \& Kim, C.H. 1995. Phytophthora blight of pepper and its control in Korea. Plant Diease, 79(3): 221-227. 
Lefebvre, V. \& Palloix, A. 1996. Both epistatic and additive effects of QTLs are involved in polygenic induced resistance to disease: a case study, the interaction pepper - Phytophthora capsici Leonian. Theoretical and Applied Genetics, 93: 503-11.

Lo Scalzo, R., Fibiani, M., Pietromarchi, P., Mandalà, C. \& La Torre, A. 2012. Effects of different fungicide treatments on grape, must and wine quality. Communications in Agricultural and Applied Biological Sciences, 77(3): 151-161.

Ristaino, J.B. \& Johnston, S.A. 1999. Ecologically based approaches to management of Phytophthora blight on bell pepper. Plant Disease, 83(12): 1080-1089.
Rusono, N., Suanri, A., Candradijaya, A., Muharam, A., Martino, I., Tejaningsih, Hadi, P.U., Susilowati, S.H. \& Maulana, M. 2013. Studi Pendahuluan Rencana Pembangunan Jangka Menengah Nasional (RPJMN) Bidang Pangan dan Pertanian 2015-2019. Direktorat Pangan dan Pertanian Kementrian Perencanaan Pembangunan Nasional/Badan Perencanaan Pembangunan Nasional, Jakarta.

Shannon, E. 1989. Chile Disease Control, Cooperative Extension Service, Guide H-219. Las Cruces, NM: New Mexico State University.

Badan Pusat Statistik (BPS). 2015. https://www.bps. go.id/linkTabelStatis/view/id/950 accessed on October 6, 2016.

Zhang, Y.L., Jia, Q.L., Li, D.W., Wang, J.E., Yin, Y.X. \& Gong, Z.H. 2013. Characteristic of the pepper CaRGA2 gene in defense responses against Phytophthora capsici Leonian. International Journal of Molecular Sciences, 14: 8985-9004. 